\title{
Direct bioconversion of brown algae into ethanol by thermophilic bacterium Defluviitalea phaphyphila
}

\author{
Shi-Qi Ji, Bing Wang, Ming Lu and Fu-Li Li
}

\begin{abstract}
Background: Brown algae are promising feedstocks for biofuel production with inherent advantages of no structural lignin, high growth rate, and no competition for land and fresh water. However, it is difficult for one microorganism to convert all components of brown algae with different oxidoreduction potentials to ethanol. Defluviitalea phaphyphila Alg1 is the first characterized thermophilic bacterium capable of direct utilization of brown algae.

Results: Defluviitalea phaphyphila Alg1 can simultaneously utilize mannitol, glucose, and alginate to produce ethanol, and high ethanol yields of $0.47 \mathrm{~g} / \mathrm{g}$-mannitol, $0.44 \mathrm{~g} / \mathrm{g}$-glucose, and $0.3 \mathrm{~g} / \mathrm{g}$-alginate were obtained. A rational redox balance system under obligate anaerobic condition in fermenting brown algae was revealed in D. phaphyphila Alg1 through genome and redox analysis. The excess reducing equivalents produced from mannitol metabolism were equilibrated by oxidizing forces from alginate assimilation. Furthermore, D. phaphyphila Alg1 can directly utilize unpretreated kelp powder, and $10 \mathrm{~g} / \mathrm{L}$ of ethanol was accumulated within $72 \mathrm{~h}$ with an ethanol yield of $0.25 \mathrm{~g} / \mathrm{g}-\mathrm{kelp}$. Microscopic observation further demonstrated the deconstruction process of brown algae cell by D. phaphyphila Alg1.
\end{abstract}

Conclusions: The integrated biomass deconstruction system of D. phaphyphila Alg1, as well as its high ethanol yield, provided us an excellent alternative for brown algae bioconversion at elevated temperature.

Keywords: Brown algae, Redox balance, Bioethanol, Marine thermophile, Defluviitalea phaphyphila

\section{Background}

To settle worldwide energy crisis and environmental problems, increased interests have been focused on aquatic and marine production for biofuels, which mainly includes biofuels derived from macroalgae and microalgae. Brown algae are a large group of marine seaweeds including almost 1800 species of macroalgae with a characteristic olive-green to dark brown color derived from fucoxanthin [1]. Some well-known aquaculture or wild species are from the genera of Laminaria, Saccharina, Macrocystis, Sargassum, and so on. The technology for the mass production of macroalgae has been developed significantly in China and Asia over the last 50 years [2]. Notably, China contributes

\footnotetext{
*Correspondence: lifl@qibebt.ac.cn

Key Laboratory of Biofuels, Shandong Provincial Key Laboratory of Synthetic Biology, Qingdao Institute of Bioenergy and Bioprocess Technology, Chinese Academy of Sciences, 189 Songling Road, Qingdao 266101, People's Republic of China
}

$72 \%$ of global aquaculture-based macroalgae production, including the genera of Laminaria (reclassified as Saccharina for some species, brown algae), Undaria (green algae), Porphyra, and Gracilaria (red algae) [3]. Brown algae have complex sugar composition, mainly including alginate, mannitol, and laminarin [3]. Alginate is the unique structural polysaccharides in brown algae, which consists of two uronic acids, namely, $\alpha$-L-guluronate $(G)$ and $\beta$-D-mannuronate $(M)$ [4]. The content of alginate varied from 20 to $40 \%$ of dry weight among different species $[5,6]$. Mannitol and laminarin are considered as reserve carbohydrates in many brown algae species, which are mostly accumulated in summer. Mannitol is a sugar alcohol form of mannose, while laminarin is a linear polysaccharide of mannitol-containing $\beta$-1,3-linked glucose [7, 8]. The content of mannitol and laminarin in some species can reach as high as 25 and $30 \%$, respectively, at the beginning of autumn [9]. 
The inherent advantages of brown algae for biofuel production mainly include the structural advantage of containing no lignin, high growth rate, and no competition with food production for land or fresh water $[1,10,11]$. They have been used for anaerobic digestion to produce biogas and liquid biofuel production. The direct bioconversion of brown algae to produce bioethanol cannot be easily achieved because of their diverse carbohydrate components. It is difficult for one microorganism to ferment all saccharides for biofuel production. Although glucose released from the hydrolysis of glucan could be easily assimilated through glycolysis by candidate strains, mannitol catabolism needs additional enzymes before entering glycolysis which include D-mannitol phosphotransferase (PTS) permease which transports D-mannitol into cells with the formation of mannitol-1-phosphate, and one mannitol-1-phosphate dehydrogenase (MPDH) (mannitol degradation I, MetaCyc Pathway Database, http://www.metacyc.org/) [12]. One reduced nicotinamide adenine dinucleotide (NADH) or reduced nicotinamide adenine dinucleotide phosphate (NADPH) was produced in this process of oxidizing mannitol-1-phosphate to fructose-6-phosphate. Moreover, the saccharification of brown algae requires one microorganism to secrete several polysaccharide depolymerizing enzymes such as alginate lyase and laminarinase. Through the endolytical and exolytical cleavages by alginate lyase and oligoalginate lyases, alginate was degraded into unsaturated monosaccharide (spontaneously rearranged into 4-deoxy-L-erythro-5-hexoseulose uronic acid, DEH) [13]. Subsequently, a DEH reductase and one 2-keto3-deoxy-D-gluconate (KDG) kinase converted DEH into 2-keto-3-deoxy-6-phosphogluconate (KDPG) with a consumption of one NADH or NADPH, and then KDPG was directly assimilated through the Entner-Doudoroff (ED) pathway $[14,15]$. In general, most ethanologenic microorganisms did not contain these genes encoding alginate depolymerizing enzymes. Thus, acid or enzymatic pretreatments were needed to decompose their structural polysaccharides to release monomer sugars from brown algae biomass [11, 16-19]. Moreover, the combined metabolism of alginate and mannitol also needs a well evolved redox system to balance the reducing equivalents, especially under anaerobic fermentation conditions [20]. Thus, in a direct bioconversion process for ethanol production, one microorganism need to secrete multiple enzymes to depolymerize polysaccharides, uptake the released sugars, metabolize the sugars, and balance the redox state of the cells. Due to these limitations, only a few natural microorganisms exhibit all the features desired for direct bioconversion of brown algae as far as we know. However, several natural strains showing partial desirable properties have been reported [17,
$21,22]$. In general, they could only utilize glucan and/or mannitol released from brown algae after acid or enzyme pretreatment for bioethanol production. To generate a viable organism with better performance in brown algae bioconversion, attempts to genetically engineer natural strains were reported. For example, Escherichia coli was engineered to a microbial platform for bioethanol production directly from brown macroalgae by introducing a DNA fragment from Vibrio splendidus encoding alginate transport and metabolism and ethanol synthesis genes ( $p d c$ and $a d h B$ ) from Zymomonas mobilis [23]. Recently, a synthetic yeast platform (S. cerevisiae) has been constructed to be able to metabolize DEH and mannitol, however, without alginate degradation ability [20]. The procedure of genetic engineering is extremely complex, and besides it is hard to meet all the requirements which favored direct fermentation processes.

In our previous work, an untapped thermophilic bacterial resource was identified from coastal sediments [24-26]. Strain Defluviitalea phaphyphila Alg1 is one of the species isolated from this environment [27]. Genome analysis indicated that strain Alg1 has an integrated brown algae-degrading system. In this work, the potential of $D$. phaphyphila Alg1 in direct bioconversion of brown algae to ethanol was investigated and evaluated.

\section{Methods}

\section{Culture media and microorganisms}

S. japonica was purchased from Tuandao seafood market in Qingdao, China. The seaweed was dried under sunlight and then ground into powder by a knife mill. The powder was filtered through a 200-mesh sieve. The basal medium (BM) consisted of $0.1 \mathrm{~g} / \mathrm{L}$ of $\mathrm{KH}_{2} \mathrm{PO} 4,0.1 \mathrm{~g} / \mathrm{L}$ of $\mathrm{K}_{2} \mathrm{HPO} 4,1 \mathrm{~g} / \mathrm{L}$ of $\mathrm{NaHCO}_{3}, 2 \mathrm{~g} / \mathrm{L}$ of $\mathrm{NH}_{4} \mathrm{Cl}, 30 \mathrm{~g} / \mathrm{L}$ of sea salt, $0.5 \mathrm{~g} / \mathrm{L}$ of L-cysteine, $0.2 \%$ of yeast extract, and $0.0001 \%(\mathrm{w} / \mathrm{v})$ of resazurin. The BM medium containing $1 \mathrm{~g} / \mathrm{L}$ of alginate (ABM) was sterilized at $115^{\circ} \mathrm{C}$ for $20 \mathrm{~min}$ and used as inoculum medium. The previously characterized type strain $D$. phaphyphila Alg1 $\left(=\right.$ CGMCC $\left.1.5199^{\mathrm{T}}=\mathrm{JCM} 30481^{\mathrm{T}}\right)$ was used as fermentation strain [27]. A seed culture (50 $\mathrm{ml} \mathrm{ABM}$ medium in anaerobic bottle) was prepared from a single colony of Alg1 from plate and incubated at $60{ }^{\circ} \mathrm{C}$ for $24 \mathrm{~h}$ until the optical density at $600 \mathrm{~nm}\left(\mathrm{OD}_{600}\right)$ reached $0.8-0.9$. For fermentation experiments, a culture was inoculated with $5 \%$ seed culture $(\mathrm{v} / \mathrm{v})$.

\section{Ethanol fermentation of $D$. phaphyphila Alg1}

Fermentations were carried out in $250 \mathrm{ml}$ bottle containing $100 \mathrm{ml} \mathrm{BM}$ at $60{ }^{\circ} \mathrm{C}$ and obligate anaerobic conditions by supplementing $1 \%(\mathrm{w} / \mathrm{v})$ of each substrate including glucose, mannitol, and alginate, respectively. A mixture of alginate, mannitol, and glucose (at a ratio of 5:8:1) with 
$3 \%$ total sugar was used to simulate the main components of brown algae [23], and was tested in the same way as above. Fermentation of S. japonica powder was carried out in 1-L bioreactors. The fermentation medium consisted of $0.5 \%$ yeast extract and $5 \%$ milled kelp powder in BM. A constant flow of pure nitrogen was bubbled into the medium to remove dissolved oxygen and to maintain anaerobic conditions through the whole fermentation process. The fermentation was carried out under static conditions without stirring. Preliminary experiments have suggested that mechanical mixing was not favored by $D$. phaphyphila Alg1 in kelp fermentation. Samples were taken periodically, and were frozen at $-20{ }^{\circ} \mathrm{C}$ until further analysis. All experiments were carried out in triplicate.

\section{Genome analysis of ethanol synthesis pathway and redox balance analysis}

The Whole Genome Shotgun project of $D$. phaphyphila Alg1 has been deposited at DDBJ/EMBL/GenBank under the accession number of JWID00000000. The version described in this paper is version JWID01000000.

The redox balance of anaerobic metabolism of glucose, mannitol, alginate, and their mixture was analyzed as follows. The cells growing in different substrates were collected in late exponential phase. An Amplite ${ }^{\mathrm{TM}}$ Colorimetric NAD/NADH Ratio Assay Kit (AAT Bioquest Inc., Sunnyvale, CA, USA) was used to measure the intracellular total NAD/NADH amount and NAD/NADH ratio in culture cells according to the manual. Briefly, NAD in the cell lysate was extracted with NAD extraction solution and converted to NADH through enzyme reaction, and then recognized by the NADH probe to give a yellow-color dye after reaction, which has the absorbance at $460 \mathrm{~nm}$. The amount of the dye generated is directly proportional to the concentration of NAD or NADH in the cell lysate.

\section{Microscopic observation of cell wall morphology change}

The morphological changes of brown algae during fermentation were examined using optical microscope (Olympus BX51, Tokyo, Japan) and transmission electron microscope (TEM) (Hitachi H-7650, Tokyo, Japan). Briefly, brown algae were cut into $2 \mathrm{~cm}$ in width and $5 \mathrm{~cm}$ in length, and were added into the fermentation bottle. After $120 \mathrm{~h}$ of fermentation, the remaining brown algae specimens were cut into $0.1-0.2 \mathrm{~cm}$ pieces. For optical microscopy, brown algae pieces were stained by $0.1 \%$ crystal violet for $10 \mathrm{~min}$ and rinsed two times with phosphate buffer. For transmission electron microscopy, cells were fixed by $2.5 \%$ glutaraldehyde solution and $1 \%$ osmic acid. Tissue was dehydrated in graded acetone starting with $30,50,70,80,90,95 \%$ for 30 min each and with 3 rinses in $100 \%$ acetone. Infiltrate with acetone/ Spurr resin (7:3) for $5 \mathrm{~h}$, acetone/Spurr (3:7) overnight and $100 \%$ Spurr resin for $5 \mathrm{~h}$. Embed tissue in fresh Spurr resin and place in $65{ }^{\circ} \mathrm{C}$ oven and polymerize for 24 h. Leica EM UC6 (Vienna, Austria) was used to prepare ultrathin sections $(70 \mathrm{~nm})$ to examine the cell ultrastructure, and uranyl acetate (2\%) was used to stain the sections.

\section{Analytical methods for cell growth, products, and enzyme activities}

Cell growth was monitored by measuring $\mathrm{OD}_{600}$ using a lambda $25 \mathrm{UV} /$ Vis spectrometer (PerkinElmer, Shelton, USA). In the case of alginate as substrate, solid particles in the medium prevented the determination of cell density with the spectral photometer, therefore, the cell growth was assessed by measuring the total protein concentrations using the Bradford assay kit (Biomed, Beijing, China) with bovine serum albumin as the standard [28]. The concentrations of mannitol, glucose, and fermentation products were determined using high-performance liquid chromatography (HPLC) equipped with an Aminex HPX-87H column (Bio-Rad, Hercules, USA). Filtered and degassed $\mathrm{H}_{2} \mathrm{SO}_{4}(5 \mathrm{mM})$ was used as eluent at a flow rate of $0.6 \mathrm{ml} / \mathrm{min}$ and the column temperature was controlled at $65^{\circ} \mathrm{C}$. Quantification of alginate was performed using the carbazole sulfuric acid method with sodium alginate as the standard [29].

The alginate lyase and laminarinase activities were determined during the fermentation of kelp powder. Alginate lyase activity was assayed by measuring the increase in absorbance at $235 \mathrm{~nm}\left(\mathrm{~A}_{235}\right)$ of the reaction products (unsaturated uronates) for $3 \mathrm{~min}$ at $70{ }^{\circ} \mathrm{C}$ in a quartz cuvette containing $2 \mathrm{ml}$ of $0.2 \%$ alginate in $100 \mathrm{mM}$ acetate/sodium acetate buffer ( $\mathrm{pH} 5.8$ ) and $10 \mu \mathrm{l}$ fermentation supernatant. One unit of activity was defined as an increase of 0.1 in $A_{235}$ per minute. Laminarinase activity was assayed by incubating laminarin solution $(1 \% \mathrm{w} / \mathrm{v}$, in $50 \mathrm{mM}$ Tris $/ \mathrm{HCl}, \mathrm{pH} 7.3)$ with fermentation supernatant at $70{ }^{\circ} \mathrm{C}$ for $3 \mathrm{~min}$. The release of reducing sugars was measured by the dinitrosalicylic (DNS) colorimetric method [30]. One unit of laminarinase activity was defined as $1 \mathrm{mg}$ of reducing sugar equivalent to $1 \mathrm{mg}$ of glucose per minute.

\section{Results and discussion}

\section{Fermentation of glucose, mannitol, and alginate} for ethanol production

The growth and ethanol fermentation properties of $D$. phaphyphila Alg1 were evaluated by employing alginate, mannitol, or glucose (laminarin monomer) as substrates. When glucose $(1 \%, \mathrm{w} / \mathrm{v})$ was used as sole carbon substrate, Alg1 showed vigorous growth after 
inoculation, and all glucose was exhausted in less than $48 \mathrm{~h}$. The maximal cell concentration $\left(\mathrm{OD}_{600}\right)$ reached 1.2 at $48 \mathrm{~h}$ (Fig. 1a). After $108 \mathrm{~h}$ cultivation, $3.8 \mathrm{~g} / \mathrm{L}$ ethanol and $0.4 \mathrm{~g} / \mathrm{L}$ acetic acid were produced, with an ethanolto-acetate ratio of 9.5:1 (Fig. 1a). The ethanol yield was $0.38 \mathrm{~g} / \mathrm{g}$-glucose which accounted for $74 \%$ of the maximal yield of $0.51 \mathrm{~g} / \mathrm{g}$-glucose [31]. In the case of mannitol $(1 \%, \mathrm{w} / \mathrm{v})$ as substrate, the cell density could reach to the highest $\mathrm{OD}_{600}$ of 1.4 after $108 \mathrm{~h}$ cultivation (Fig. 1b). The concentrations of ethanol and acetic acid could be as high as 4.3 and $0.3 \mathrm{~g} / \mathrm{L}$, respectively, with an ethanol-toacetate ratio around 14:1 (Fig. 1b). The ethanol yield from mannitol was about $0.44 \mathrm{~g} / \mathrm{g}$-mannitol, which accounted for $86 \%$ of the theoretical maximal yield of $0.51 \mathrm{~g} / \mathrm{g}$ mannitol [8]. Mannitol was exhausted until $108 \mathrm{~h}$ indicating a slower substrate assimilation rate than glucose. Indeed, from the reported literatures, mannitol normally cannot be fermented under strictly anaerobic condition by Zymobacter palmae, Enterobacter sp. JMP3 and some yeast species, while glucose can be easily converted to ethanol under the same condition. Thus, the utilization of mannitol is more complex, and has higher requirements on microorganisms. In addition, in contrast to those of Z. palmae (0.38 g-ethanol/g-mannitol) and Enterobacter sp. (0.29 g-ethanol/g-mannitol) [8, 22], D. phaphyphila Alg1 showed the highest ethanol conversion rate of 0.44 g-ethanol/g-mannitol, which suggests Alg1 is a potential strain for mannitol bioconversion. Alginate could not be fully dissolved in the medium for the gelling property in the presence of divalent ion. Thus, total protein concentration of cells was used to monitor the growth of $D$. phaphyphila Alg1 in the case of alginate fermentation. Cells showed vigorous growth in first $48 \mathrm{~h}$, suggesting alginate is favored by Alg1, and a total of $7.6 \mathrm{~g} / \mathrm{L}$ alginate was consumed after $108 \mathrm{~h}$ (Fig. 1c). Totally, $2.7 \mathrm{~g} / \mathrm{L}$ ethanol and $3 \mathrm{~g} / \mathrm{L}$ acetic acid were produced, with an ethanol-to-acetate ratio of 0.9:1. It can be concluded that $D$. phaphyphila Alg1 could successfully convert alginate into ethanol and acetate, and its products contained more acetic acid than those from glucose and mannitol. It is worth to mention that no natural strains have been reported to ferment alginate, which might attribute to the fact that alginate needs a complex system for decomposition, and the resulting uronic acid is not easily converted by strains without ED pathway. This indicates that D. phaphyphila Alg1 has good potential for ethanol production from seaweed compared to other reported strains $[1,11,21,32]$.

One of the most important characteristics shared by Alg1 is that it is a thermophilic strain producing high concentration of ethanol, which was very rare in the previous reports. The effects of cultivation temperature on ethanol yields were evaluated in this work. The growth

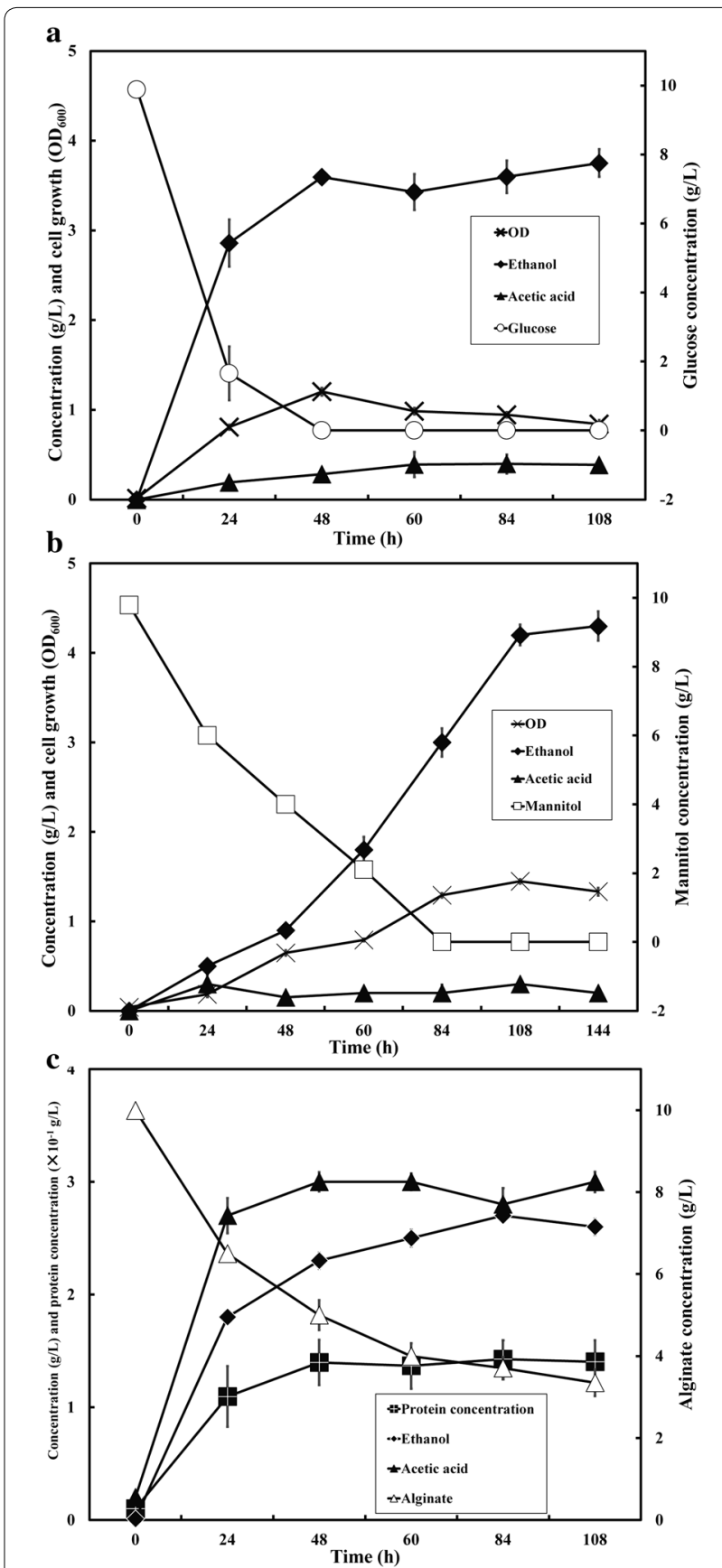

Fig. 1 Microbial growth, substrate consumption, and ethanol production of D. phaphyphila Alg1 with the substrates of glucose (1\% $\mathrm{w} / \mathrm{V}, \mathbf{a})$, mannitol $(1 \% \mathrm{w} / \mathrm{v}, \mathbf{b})$, and alginate $(1 \% \mathrm{w} / \mathrm{V}, \mathbf{c})$

temperatures of $D$. phaphyphila Alg1 were from 45 to $65^{\circ} \mathrm{C}$ based on the previous work [27]. Accordingly, three temperatures $\left(45,50\right.$, and $\left.60{ }^{\circ} \mathrm{C}\right)$ were chosen to estimate the effects on ethanol yields. As shown in Fig. 2, D. phaphyphila Alg1 showed higher ethanol productivities at both 50 and $60{ }^{\circ} \mathrm{C}$ than at $45{ }^{\circ} \mathrm{C}$. The highest ethanol 


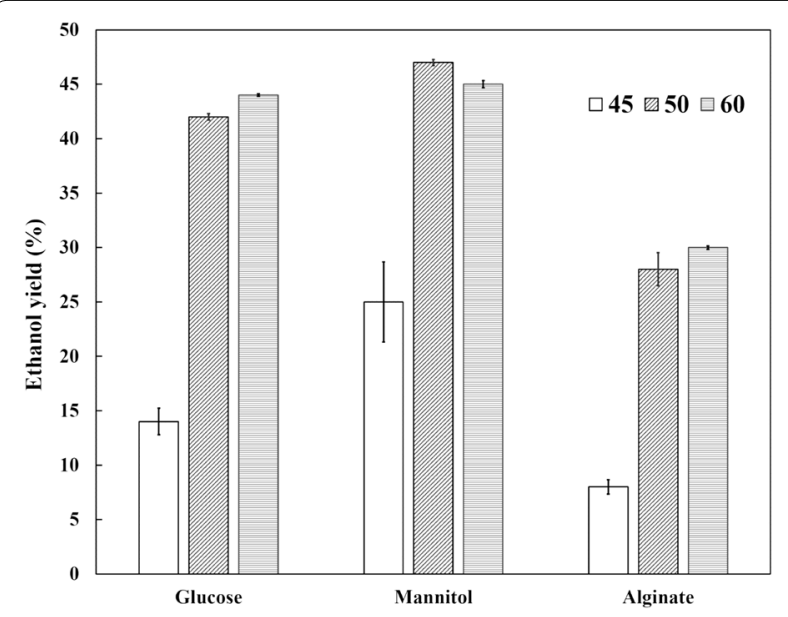

Fig. 2 Ethanol yields of D. phaphyphila Alg1 from glucose, mannitol, and alginate under different temperatures

yields for glucose and alginate were at $60{ }^{\circ} \mathrm{C}$, which were $0.44 \mathrm{~g} / \mathrm{g}$-glucose and $0.3 \mathrm{~g} / \mathrm{g}$-alginate. The ethanol yields for mannitol did not show significant difference at 50 and $60{ }^{\circ} \mathrm{C}$, which were $0.44 \mathrm{~g} / \mathrm{g}$-mannitol and $0.42 \mathrm{~g} / \mathrm{g}$-mannitol, respectively. It can be concluded that Alg1 showed better substrate conversion rates between 50 and $60{ }^{\circ} \mathrm{C}$. Thus, $D$. phaphyphila Alg1 turned out to be a unique thermophilic ethanologenic bacterial strain with high ethanol yields from glucose, mannitol, and alginate.

\section{Genome analysis of ethanol synthesis pathway and redox balance analysis}

Ethanol synthesis from the three major components of brown algae-glucose, mannitol, and alginate was analyzed from genome information. As shown in Fig. 3, the ethanologenesis starts with the formation of pyruvate through EMP (Embden-Meyerhof-Parnas) pathway and ED pathway, and pyruvate is then converted to acetyl-CoA by pyruvate:ferredoxin oxidoreductase (PFO) encoded by Dp0079 and Dp1929. Lastly, ethanol was produced from acetyl-CoA by a bifunctional alcohol and aldehyde dehydrogenase (AdhE, Dp0288) which shared $67 \%$ of identity with the AdhE of Thermoanaerobacterium saccharolyticum with consumption of 2 NADH [33], and acetate was produced by a phosphate acetyltransferase (PAT, Dp0236) and an acetate kinase (Dp0235) without consumption of NADH (Fig. 3). Through the genome analysis, it can be concluded that D. phaphyphila Alg1 utilizes a pathway containing PFO to assimilate pyruvate. This pathway, which was also found in a famous engineered thermophilic bacterium Thermoanaerobacterium saccharolyticum with high ethanol titer, is different from that in previously described microbes with homoethanol fermentation
[34]. According to the metabolic pathway, to produce 2 ethanol, the net consumptions of NADH for glucose and mannitol were $2 \mathrm{NADH}$ and $1 \mathrm{NADH}$, respectively (Fig. 3). To produce 2 acetate, $2 \mathrm{NADH}$ and $3 \mathrm{NADH}$ were generated in the catabolism of glucose and mannitol, respectively. In the case of alginate assimilation, the feasible pathway of producing ethanol from this polysaccharide was rather rare in microorganisms. To decompose alginate, it was firstly depolymerized into $\mathrm{DEH}$, and then NADH-dependent DEH reductases (DehR) were employed to produce KDG; lastly, KDG was fed into the ED pathway to produce pyruvate and glyceraldehyde-3-phosphate (G3P) by 2-keto-3-deoxyglucononate kinase (KdgK) and KDPG aldolase (KdpgA), which has been discussed in our previous work [27]. During this process, $1 \mathrm{NADH}$ was consumed by DehR, and thus would cause the deficiency of reducing equivalents. To generate 2 ethanol, $4 \mathrm{NADH}$ were consumed, while $\mathrm{NADH}$ maintained a balance in generating 2 acetate. The vigorous growth in mannitol, glucose, and alginate under obligate anaerobic condition indicated that $D$. phaphyphila Alg1 could well balance the redox level.

To figure out the redox balance in metabolism of mannitol, glucose, alginate, and their mixture, the NAD/ $\mathrm{NADH}$ ratio in the cells was analyzed (Table 1). In accordance with the results of genome analysis, the low $\mathrm{NAD} / \mathrm{NADH}$ ratio $(0.63 \pm 0.15)$ in mannitol metabolism indicated that excessive reducing equivalents were produced, while the high NAD/NADH ration $(7.93 \pm 1.07)$ in alginate assimilation indicated a deficiency of reducing equivalents (Table 2). Alg1 showed a middle NAD/ NADH ratio $(3.48 \pm 0.57)$ when fermenting the mixture of alginate, mannitol, and glucose $(5: 8: 1)$ simulating the main components of brown algae. Through these results, it can be concluded that the different oxidoreduction potentials in substrates of glucose, mannitol, and alginate finally affected the metabolic flux into ethanol pathway. Ethanol production highly consums reducing equivalents. On the one hand, the lack of NADH could explain a low ethanol-to-acetate ratio in alginate degradation, which means production of acetic acid was a direct response to deficiency of reducing power. On the other hand, the consumption of excess reducing equivalents is also important in balancing the redox potential. The redox balance is hard to control especially in engineered strains. For example, Sphingomonas sp. A1 was engineered to produce ethanol from alginate, and oxygen supply should be strictly controlled to maintain the redox balance between energy supplement and ethanol production [6]. Even under precise control, Sphingomonas sp. strain A1 could only reach an ethanol yield of $0.25 \mathrm{~g} / \mathrm{g}$-alginate which was lower than that of strain Alg1 (0.3 g/g-alginate). 


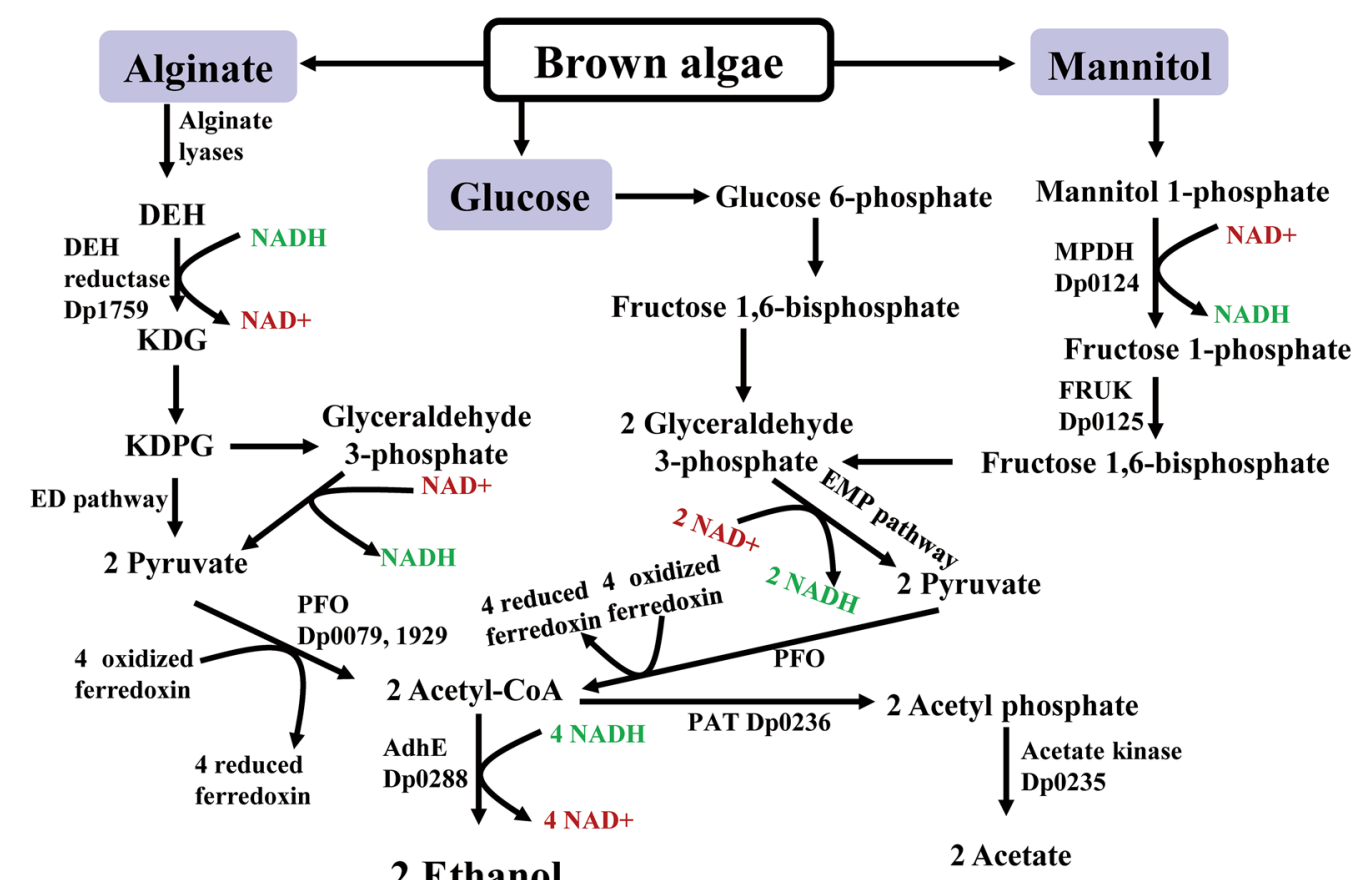

Fig. 3 Genome analysis of the metabolic pathways and redox balance of ethanol synthesis in D. phaphyphila Alg1. EMP Embden-Meyerhof-Parnas; ED Entner-Doudoroff; AdhE bifunctional alcohol and aldehyde dehydrogenase; PFO pyruvate ferredoxin oxidoreductase; PAT phosphate acetyltransferase; MPDH mannitol-1-phosphate dehydrogenase; FRUK 1-phosphofructokinase

Table 1 The redox states of D. phaphyphila Alg1 in fermenting different sugars of brown algae

\begin{tabular}{llll}
\hline & NAD + NADH & NAD & NAD/NADH \\
\hline Mannitol & $1.77 \pm 0.12$ & $0.60 \pm 0.16$ & $0.63 \pm 0.15$ \\
Glucose & $1.75 \pm 0.70$ & $1.17 \pm 0.42$ & $2.51 \pm 0.51$ \\
Alginate & $2.70 \pm 0.52$ & $2.45 \pm 0.44$ & $7.93 \pm 1.07$ \\
Sugar mixture $^{a}$ & $2.18 \pm 0.15$ & $1.69 \pm 0.53$ & $3.48 \pm 0.57$ \\
\hline
\end{tabular}

a Sugar mixture contained alginate, mannitol and glucose with a ratio of 5:8:1

The different oxidoreduction potentials of glucose, mannitol, and alginate make the bioconversion of brown algae very difficult. The deficiency of reducing equivalents in alginate metabolism, and the highly reducing equivalents consumption during ethanol formation can easily cause serious redox imbalance. No natural microorganisms have been reported to be capable of converting alginate to ethanol as far as we know. As mentioned above, mannitol is also hard to be converted to ethanol under anaerobic condition in Z. palmae, Enterobacter sp. JMP3, and some yeast species. Mannitol fermentation would produce excess electrons in contrast to alginate. Under anaerobic condition, these excess reducing equivalents could not be neutralized by oxygen, especially when the microorganisms lack transhydrogenase (an enzyme converting catabolic reducing equivalent $\mathrm{NADH}$ to anabolic reducing equivalent $\mathrm{NADPH})[8,35]$. However, the redox

Table 2 Microorganisms that convert brown seaweed biomass to ethanol

\begin{tabular}{|c|c|c|c|c|}
\hline Microorganism & Characteristics & Major sugars utilized & Pretreatment & References \\
\hline D. phaphyphila Alg1 & Thermophilic Nat & Mannitol, alginate, laminarin & Un-pretreatment & This study \\
\hline Zymobacter palmae & Nat & Mannitol, laminarin & Thermal acid hydrolysis & {$[8,39]$} \\
\hline Pichia angophorae & Nat & Monosaccharide & Thermal acid hydrolysis & {$[32]$} \\
\hline Saccharomyces cerevisiae & Nat & Glucose & Laminarinase & {$[17]$} \\
\hline Escherichia coli BAL1611 & Eng & Mannitol, alginate, glucose & Un-pretreatment & {$[23]$} \\
\hline Escherichia coli KO11 & Eng & Glucose, mannitol & Acid and hydrolytic enzymes & {$[11]$} \\
\hline Sphingomonas sp. A1 & Eng & Alginate & N/A & {$[6]$} \\
\hline Saccharomyces cerevisiae BAL3215 & Eng & Mannitol, glucose, DEH & $\mathrm{N} / \mathrm{A}$ & {$[20]$} \\
\hline
\end{tabular}


problem was well solved in $D$. phaphyphila by integrating two complementary pathways which were hard to proceed individually to reach equilibrium. These results provide insights into mechanisms of redox balancing in fermentation of brown algae, and will assist future metabolic engineering efforts on D. phaphyphila.

\section{Ethanol fermentation of brown algae by D. phaphyphila Alg1}

An artificial mixed sugar simulating the main components of brown algae with a ratio of alginate:mannitol:gl ucose $=5: 8: 1$ (3\% total sugar) was used to evaluate the fermentation properties of Alg1, which would help us to have a comprehensive understanding of the fermentation process. As shown in Fig. 4a, a total of $7.8 \mathrm{~g} / \mathrm{L}$ ethanol and $1.2 \mathrm{~g} / \mathrm{L}$ acetic acid were produced with a consumption of $24.2 \mathrm{~g} / \mathrm{L}$ total sugars. The ethanol-to-acetate ratio and ethanol yield were calculated to be $6.5: 1$ and $0.32 \mathrm{~g} / \mathrm{g}$-total sugar, respectively. The contents of alginate, mannitol, and glucose decreased quickly after $24 \mathrm{~h}$ fermentation, and a simultaneous consumption of them was observed during 24-48 h. It can be concluded that D. phaphyphila Alg1 could simultaneously saccharify and ferment the three main components of brown algae, and although these components have different oxidoreduction potentials, reducing equivalents are well balanced and metabolic flux is directed into ethanol production in this strain.

We further used $5 \%(\mathrm{w} / \mathrm{v})$ kelp powder (dry weight $48 \mathrm{~g})$ to evaluate the ethanol production ability of $D$. phaphyphila Alg1 in 1-L bioreactors. Through $72 \mathrm{~h}$ fermentation, $10 \mathrm{~g} / \mathrm{L}$ of ethanol and $3.2 \mathrm{~g} / \mathrm{L}$ of acetic acid were produced (Fig. 4b). Mannitol was released to the medium immediately after the kelp powder was added with a concentration of $8 \mathrm{~g} / \mathrm{L}$. Initially, glucose was undetectable, while an increasing amount of glucose was observed after the initial cell growth, suggesting that the secreted hydrolases caused the degradation of laminarin and the release of glucose. This hypothesis process was confirmed in the enzyme activity assay (Fig. 4b). At the end of fermentation, a total of $40 \mathrm{~g} / \mathrm{L}$ kelp powder was consumed, corresponding to an ethanol yield of $0.25 \mathrm{~g} / \mathrm{g}$-kelp.

As an emerging feedstock for liquid biofuel production, brown algae bioconversion has been extensively studied. Some of the studies on converting brown seaweed to ethanol are listed in Table 2. Both natural and engineered strains were employed for bioconversion. For most studies, a multiple-step process with acid and/or enzymatic pretreatments before fermentation was used. For example, Kim et al. used E. coli KO11 to ferment $S$. japonica with acid pretreatment and enzymatic hydrolysis, and the study resulted in an ethanol yield of $0.4 \mathrm{~g} / \mathrm{g}$
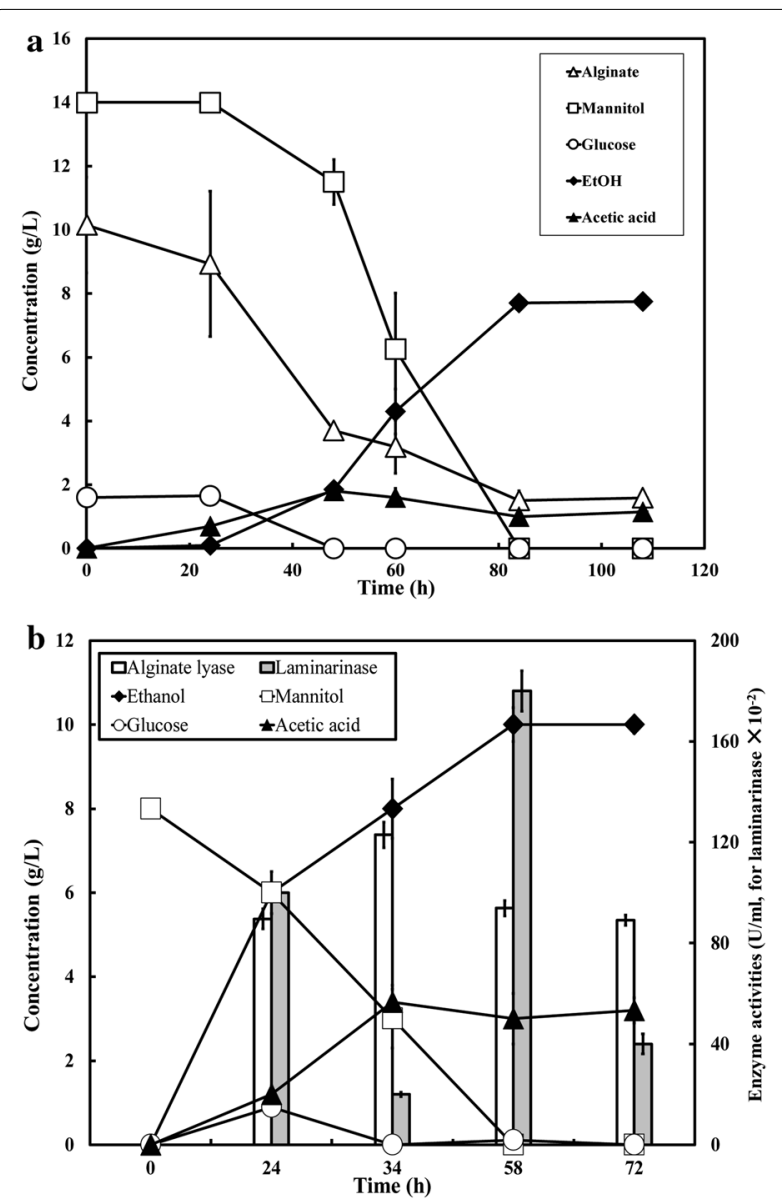

Fig. 4 Fermentation properties of D. phaphyphila Alg1 using mix sugars (alginate:mannitol:glucose $=5: 8: 1$ ) simulating main components of brown algae (a) and kelp powder $(\mathbf{b})$ as substrates

of sugars [11]. In spite of the high ethanol yield of strain KO11, it still lacks the ability of biomass saccharification. The inability of alginate and mannitol fermentation by natural ethanologenic microorganisms can be concluded from Table 2. The low ethanol yield of yeast was likely due to its inability in utilizing mannitol. The molecular basis of this inability of mannitol assimilation in S. cerevisiae was illustrated very recently [36]. Some specific engineered strains have displayed excellent performance in assimilating unpretreated brown algae. The ethanol yield of $E$. coli strain BAL1611 was $0.29 \mathrm{~g} / \mathrm{g}$-seaweed at $25{ }^{\circ} \mathrm{C}$ [23]. Compared with these previous studies, there are two impressive characteristics of $D$. phaphyphila Alg1 in brown algae bioconversion. Firstly, D. phaphyphila Alg1 is an obligate anaerobic and thermophilic bacterium, which can ferment brown algae under elevated temperatures up to $60{ }^{\circ} \mathrm{C}$. Thermophilic bacteria could offer the advantages for ethanol production such as low contamination risk [37]. Secondly, D. phaphyphila Alg1 can directly assimilate unpretreated brown algae with 

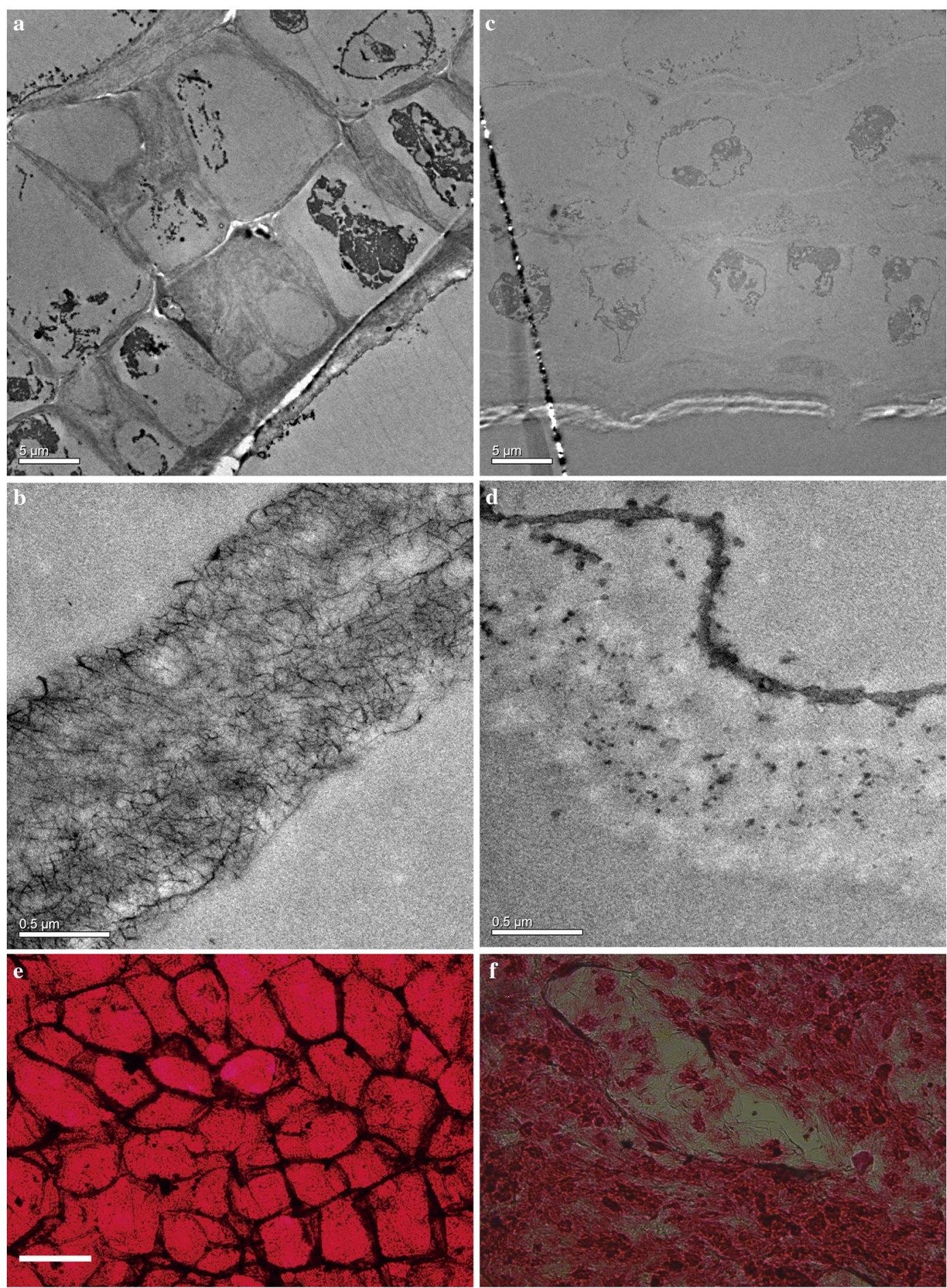

Fig. 5 Transmission electron microscope (TEM) and optical microscope images of brown algae samples, unfermented brown algae (a, b, e), and brown algae after fermentation (c, d, f). e, f stained with azaleine, and scale bars $100 \mu \mathrm{m}$

high ethanol conversion rate, and can simultaneously ferment the mannitol, laminarin, and alginate, which are highly advantageous over most microorganisms. In a word, D. phaphyphila Alg1 possesses not only extracellular polymer-degrading enzymes such as alginase and laminarinase for saccharification but also good ethanol 
production ability, which would potentially provide it advantages in bioconversion process. Similar to the consolidated bioprocessing (CBP) process in the conversion of lignocellulose into biofuel in one step, the direct conversion of brown algae to ethanol has potential to lower the cost of biomass processing due to elimination of operating and capital costs associated with dedicated enzyme production and/or thermal acid hydrolysis, and a more effective biomass solubilization could be achieved [38]. More than that, the ethanol yields of these strains used in the two-step methods were lower than that of $D$. phaphyphila because of their inability of utilizing monomers of alginate and/or mannitol.

\section{Biodegradation characteristics of brown alga cell wall}

To elucidate the biodegradation characteristics of $D$. phaphyphila Alg1 on brown algae, strips of S. japonica was used as substrate. The morphological changes induced by incubation with $D$. phaphyphila Alg1 were examined by both transmission electron microscope (TEM) and optical microscope to provide direct insight into the structure modification of the biomass. Before fermentation, a high electron density of the cell walls observed by TEM indicated the cell integrity (Fig. 5a, c). Similarly, ordered cell walls could be easily recognized by optical microscope after being stained with azaleine (Fig. 5e), and the cell showed high mechanical strength. After $120 \mathrm{~h}$ fermentation by $D$. phaphyphila Alg1, the morphology of residual brown algae changed dramatically. The electron density of the cell walls became very light (Fig. 5b, d). From optical microscopy, the initial ordered cell structures were destroyed, and were subsequently presented as collapsed and incomplete cell structures (Fig. 5f). Obviously, the cell wall components sustaining cell morphology which are mainly composed of alginate and glucan were largely degraded during fermentation. In addition to microscopic observation, the activities of corresponding depolymerizing enzymes during fermentation of brown seaweed were analyzed. As shown in Fig. 4b, alginate lyase and laminarinase activities were detected. The alginate lyase activity increased rapidly before $24 \mathrm{~h}$ and reached a maximum level after $34 \mathrm{~h}$ of incubation at $123 \mathrm{U} / \mathrm{mL}$. This activity maintained at a high level during fermentation, indicating Alg1 has an evolved thermostable alginolytic system which has been proved in previous work [27]. The laminarinase activity was consistent with the appearance of glucose. High activity was detected at $24 \mathrm{~h}$, and the highest concentration of glucose was achieved at the same time, which meant that laminarinase caused the release of glucose from laminarin. The high concentration of glucose might cause a negative feedback inhibition of the laminarinase gene expression. In the next $10 \mathrm{~h}$, no more laminarinases were produced, and the formerly synthesized laminarinases gradually lost their activities. Therefore, the laminarinase activity became weaker at $34 \mathrm{~h}$. At the same time, glucose was consumed immediately, and was exhausted at $34 \mathrm{~h}$. The inhibition of laminarinase gene was relieved accordingly, and more laminarinases were synthesized to produce more glucose. The result is that laminarinase activity undergoing a short decrease achieved the maximum activities of $1.8 \mathrm{U} / \mathrm{mL}$ at $58 \mathrm{~h}$ (Fig. 4b). However, only small amount of glucose was detected at this time for most of laminarin had been hydrolyzed. These results further confirmed the decomposition of unpretreated brown algae cell walls and their polysaccharides by strain Alg1.

\section{Conclusions}

Defluviitalea phaphyphila Alg1 showed remarkable ethanol production ability in assimilating brown algae. High ethanol yields of $0.44,0.47$, and $0.3 \mathrm{~g} / \mathrm{g}$ of sugars were obtained by fermenting glucose, mannitol, and alginate at $60{ }^{\circ} \mathrm{C}$, respectively. An ethanol yield of $0.25 \mathrm{~g} / \mathrm{g}$-biomass was obtained in fermenting unpretreated kelp. Genome and redox analysis revealed a well evolved redox balance system in Alg1 in fermenting brown algae. The elucidation of the redox balances of substrates with different oxidoreduction potentials would help us increase ethanol productivity. This novel bacterium provides a potential gene-manipulable platform for high-value chemical production from brown algae at elevated temperature.

\begin{abstract}
Abbreviations
PTS: phosphotransferase; MPDH: mannitol-1-phosphate dehydrogenase; $\mathrm{NADPH}$ : reduced nicotinamide adenine dinucleotide phosphate; $\mathrm{NADH}$ : reduced nicotinamide adenine dinucleotide; DEH: 4-deoxy-L-erythro-5-hexoseulose uronic acid; KDG: 2-keto-3-deoxy-D-gluconate; KDPG: 2-keto-3-deoxy6-phosphogluconate; ED: Entner-Doudoroff; HPLC: high-performance liquid chromatography; DNS: dinitrosalicylic; EMP pathway: Embden-Meyerhof-Parnas pathway; PFO: pyruvate:ferredoxin oxidoreductase; AdhE: bifunctional alcohol and aldehyde dehydrogenase; PAT: phosphate acetyltransferase; FRUK: 1-phosphofructokinase; DehR: 4-deoxy-L-erythro-5-hexoseulose uronic acid reductases; G3P: glyceraldehyde-3-phosphate; KdgK: 2-keto-3-deoxyglucononate kinase; KdpgA: 2-keto-3-deoxy-6-phosphogluconate aldolase; TEM: transmission electron microscope.
\end{abstract}

\section{Authors' contributions}

SQJ and FLL conceived and designed the study. SQJ, BW, and ML performed experiments and analyzed the data. SQJ and FLL interpreted the data and wrote the manuscript. All authors read and approved the final manuscript.

\section{Acknowledgements \\ This work was supported by grants from the National Natural Science Funds of China (No. 41506155), the Science and Technology Develop Project of Shan- dong province (No. 2014GHY115027), the Shandong Province Natural Science Funds for Distinguished Young Scholar (No. JQ201507), and the Qingdao Institute of Biomass Energy and Bioprocess Technology Director Innovation Foundation for Young Scientists (No. Y37207210B).}

\section{Competing interests}

The authors declare that they have no competing interests. 
Received: 14 December 2015 Accepted: 22 March 2016 Published online: 01 April 2016

\section{References}

1. Wei N, Quarterman J, Jin Y. Marine macroalgae: an untapped resource for producing fuels and chemicals. Trends Biotechnol. 2013;31:70-7.

2. Hughes AD, Kelly MS, Black KD, Stanley MS. Biogas from Macroalgae: is it time to revisit the idea? Biotechnol Biofuels. 2012:5:86.

3. Roesijadi G, Jones SB, Snowden-Swan LJ, Zhu Y. Macroalgae as a biomass feedstock: a preliminary analysis. Richland: Pacific Northwest National Laboratory (PNNL); 2010.

4. Yamasaki M, Ogura K, Hashimoto W, Mikami B, Murata K. A structural basis for depolymerization of alginate by polysaccharide lyase family-7. J Mol Biol. 2005;352:11-21.

5. Kloareg B. Isolation and analysis of cell-walls of the brown marinealgae Pelvetia canaliculata and Ascophyllum nodosum. Physiol Veg. 1984:22:47-56.

6. Takeda H, Yoneyama F, Kawai S, Hashimoto W, Murata K. Bioethanol production from marine biomass alginate by metabolically engineered bacteria. Energy Environ Sci. 2011;4:2575-81.

7. Fleming M, Manners DJ, Masson AJ. The enzymic degradation of laminarin. Biochem J. 1967;104:32-3.

8. Horn SJ, Aasen IM, Østgaard K. Production of ethanol from mannitol by Zymobacter palmae. J Ind Microbiol Biot. 2000;24:51-7.

9. Jensen A, Haug A. Geographical and seasonal variation in the chemical composition of Laminaria hyperborea and Laminaria digitata from the Norwegian coast. Rep Norw Inst Seaweed Res No. 14, Department of Biotechnology, Trondheim: Akademisk trykningssentral; 1956.

10. Daroch M, Geng S, Wang GY. Recent advances in liquid biofuel production from algal feedstocks. Appl Energ. 2013;102:1371-81.

11. Kim NJ, Li H, Jung K, Chang HN, Lee PC. Ethanol production from marine algal hydrolysates using Escherichia coli KO11. Bioresource Technol. 2011;102:7466-9.

12. Caspi $R$, Altman T, Billington $R$, Dreher $K$, Foerster $H$, Fulcher $C A$, Holland TA, Keseler IM, Kothari A, Kubo A, et al. The MetaCyc database of metabolic pathways and enzymes and the BioCyc collection of pathway/ genome databases. Nucleic Acids Res. 2014;42:D459-71.

13. Wang B, Ji SQ, Lu M, Li FL. Biochemical and structural characterization of alginate lyases: an update. Curr Biotech. 2016. doi:10.2174/221155010466 6150723231423.

14. Preiss J, Ashwell G. Alginic acid metabolism in bacteria. 1. Enzymatic formation of unsaturated oligosaccharides and 4-deoxy-L-erythro-5-hexoseulose uronic acid. J Biol Chem. 1962;237:309-16.

15. Preiss J, Ashwell G. Alginic acid metabolism in bacteria. 2. Enzymatic reduction of 4-deoxy-L-erythro-5-hexoseulose uronic acid to 2-keto3-deoxy-D-gluconic acid. J Biol Chem. 1962;237:317-21.

16. Liu HY, Wang GC. Fermentative hydrogen production from macro-algae Laminaria japonica using anaerobic mixed bacteria. Int J Hydrogen Energ. 2014;39:9012-7.

17. Adams JM, Gallagher JA, Donnison IS. Fermentation study on Saccharina latissima for bioethanol production considering variable pre-treatments. J Appl Phycol. 2008;21:569-74.

18. Jang JS, Cho Y, Jeong GT, Kim SK. Optimization of saccharification and ethanol production by simultaneous saccharification and fermentation (SSF) from seaweed, Saccharina japonica. Bioproc Biosyst Eng. 2012;35:11-8

19. Lee J, Li P, Lee J, Ryu HJ, Oh KK. Ethanol production from Saccharina japonica using an optimized extremely low acid pretreatment followed by simultaneous saccharification and fermentation. Bioresour Technol. 2013;127:119-25
20. Enquist-Newman M, Faust AME, Bravo DD, Santos CNS, Raisner RM, Hanel A, Sarvabhowman P, Le C, Regitsky DD, Cooper SR, et al. Efficient ethanol production from brown macroalgae sugars by a synthetic yeast platform. Nature. 2014;505:239-43.

21. Lee SM, Lee $\mathbf{J H}$. Ethanol fermentation for main sugar components of brown-algae using various yeasts. J Ind Eng Chem. 2012;18:16-8.

22. Wang J, Kim YM, Rhee HS, Lee MW, Park JM. Bioethanol production from mannitol by a newly isolated bacterium, Enterobacter sp. JMP3. Bioresour Technol. 2013;135:199-206.

23. Wargacki AJ, Leonard E, Win MN, Regitsky DD, Santos CN, Kim PB, Cooper SR, Raisner RM, Herman A, Sivitz AB, et al. An engineered microbial platform for direct biofuel production from brown macroalgae. Science. 2012;335:308-13.

24. Ji SQ, Wang SA, Tan Y, Chen XH, Schwarz W, Li FL. An untapped bacterial cellulolytic community enriched from coastal marine sediment under anaerobic and thermophilic conditions. FEMS Microbiol Lett. 2012;335:39-46.

25. Ji SQ, Meng DD, Zhang KD, Li FL. Diversity of thermophilic microorganisms and their roles in carbon cycle. In: Li F-L, editor. Thermophilic microorganisms. Wymondham: Caister Academic Press; 2015. p. 13-46.

26. Wang B, Ji SQ, Tian XX, Qu LY, Li FL. Brassicibacter thermophilus sp nov a thermophilic bacterium isolated from coastal sediment. Int J Syst Evol Microbiol. 2015;65:2870-4

27. Ji SQ, Wang B, Lu M, Li FL. Defluviitalea phaphyphila sp nov., a novel thermophilic bacterium that degrades brown algae. Appl Environ Microbiol. 2016;82:868-77.

28. Bradford MM. A rapid and sensitive method for the quantitation of microgram quantities of protein utilizing the principle of protein-dye binding. Anal Biochem. 1976;72:248-54.

29. Blumenkr N, Asboehan G. New method for quantitative-determination of uronic acids. Anal Biochem. 1973:54:484-9.

30. Miller GL. Use of dinitrosalicylic acid reagent for determination of reducing sugar. Anal Chem. 1959;31:426-8.

31. Erdei B, Barta Z, Sipos B, Reczey K, Galbe M, Zacchi G. Ethanol production from mixtures of wheat straw and wheat meal. Biotechnol Biofuels. 2010;3:16

32. Cho Y, Kim H, Kim SK. Bioethanol production from brown seaweed, Undaria pinnatifida, using $\mathrm{NaCl}$ acclimated yeast. Bioproc Biosyst Eng. 2013;36:713-9.

33. Lo J, Zheng T, Hon S, Olson DG, Lynd LR. The bifunctional alcohol and aldehyde dehydrogenase gene, $a d h E$, is necessary for ethanol production in Clostridium thermocellum and Thermoanaerobacterium saccharolyticum. J Bacteriol. 2015;197:1386-93.

34. Shaw AJ, Podkaminer KK, Desai SG, Bardsley JS, Rogers SR, Thorne PG, Hogsett DA, Lynd LR. Metabolic engineering of a thermophilic bacterium to produce ethanol at high yield. Proc Natl Acad Sci USA. 2008;105:13769-74.

35. Vandijken JP, Scheffers WA. Redox Balances in the Metabolism of Sugars by Yeasts. FEMS Microbiol Lett. 1986;32:199-224.

36. Chujo M, Yoshida S, Ota A, Murata K, Kawai S. Acquisition of the ability to assimilate mannitol by Saccharomyces cerevisiae through dysfunction of the general corepressor Tup1-Cyc8. Appl Environ Microbiol. 2015;81:9-16.

37. Taylor MP, Eley KL, Martin S, Tuffin MI, Burton SG, Cowan DA. Thermophilic ethanologenesis: future prospects for second-generation bioethanol production. Trends Biotechnol. 2009;27:398-405.

38. Olson DG, McBride JE, Shaw AJ, Lynd LR. Recent progress in consolidated bioprocessing. Curr Opin Biotechnol. 2012;23:396-405.

39. Horn SJ, Aasen IM, Østgaard K. Ethanol production from seaweed extract. J Ind Microbiol Biot. 2000;25:249-54. 